\title{
ORDERED DEFECT STRUCTURES IN IRRADIATED METALS*
}

\author{
by \\ G. L. Kulcinski \\ J. L. Brimhall \\ Battelle Memorial Institute \\ Pacific Northwest Laboratories \\ Richland, Washington 99352
}

To be presented at the U.S. -Japan Seminar on

"Radiation Effects in Metals and Structural

Materials" to be held in Kyoto, Japan, September $28-30,1971$.

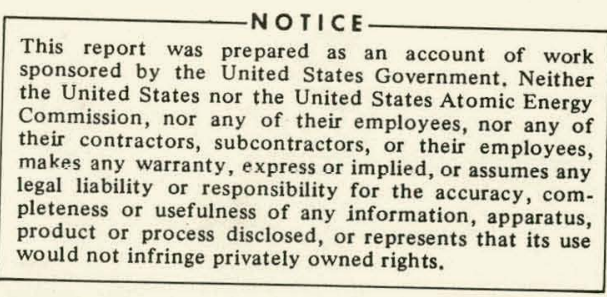

* This paper is based on work performed under United States Atomic Energy Commission Contract AT(45-1)-1830. 


\section{DISCLAIMER}

This report was prepared as an account of work sponsored by an agency of the United States Government. Neither the United States Government nor any agency Thereof, nor any of their employees, makes any warranty, express or implied, or assumes any legal liability or responsibility for the accuracy, completeness, or usefulness of any information, apparatus, product, or process disclosed, or represents that its use would not infringe privately owned rights. Reference herein to any specific commercial product, process, or service by trade name, trademark, manufacturer, or otherwise does not necessarily constitute or imply its endorsement, recommendation, or favoring by the United States Government or any agency thereof. The views and opinions of authors expressed herein do not necessarily state or reflect those of the United States Government or any agency thereof. 


\section{DISCLAIMER}

Portions of this document may be illegible in electronic image products. Images are produced from the best available original document. 
INTRODUCTION

It has been generally accepted that irradiation of high purity metals produces a completely random array of microscopic defect clusters. This observation was supported by transmission electron microscopy observations over the past $10-15$ years $(1,2)$ and was especially true in the matrix far from internal surfaces such as grain boundaries or precipitates. However, scientists have recently discovered ${ }^{(3-5)}$ that the concept of a completely random array is no longer true under certain circumstances, namely, when metals are irradiated at approximately one-third of their melting point at a fluence which corresponds to every atom being displaced many times. Such irradiations produce high densities of defect clusters whose strain fields interact and cause the defects to seek an ordered array that will minimize the total energy of the system. It is the object of this paper to present some examples of ordered loop and void structures in pure metals observed at Battelle Northwest laboratories, and to briefly review the information on ordered void structures obtained at other facilities.

EXPERIMENTAL

Descriptions of the sample material ${ }^{(6)}$ used for the BNW studies, irradiation techniques, ${ }^{(7)}$ analys is procedures $(6,8)$ and methods for calculating the damage in the samples $(9,10)$ are given elsewhere. Briefly, $3 \mathrm{~mm}$ diameter samples were irradiated on a temperature controlled furnace with high energy heavy ions. The bombarding species were either $5 \mathrm{MeV} \mathrm{Ni}, 6 \mathrm{MeV}$ Se ions, or $7.5 \mathrm{MeV} \mathrm{Ta}$ ions. A specific amount of the damage layer was removed and the samples prepared for observation with a $200 \mathrm{KV}$ electron microscope.

ORDERED LOOP STRUCTURE IN NICKEL

Irradiation of high purity nickel at temperatures of 370,400 and $450{ }^{\circ} \mathrm{C}$ to approximately $15 \mathrm{dpa}$ with $5 \mathrm{MeV} \mathrm{Ni}$ ions produced microstructures similar to that in Figure 1. The defect structure is characterized by a high density of black spots and dislocation loops aligned in mutually perpendicular rows. The foils have a very strong $\{100\}$ texture and the rows are aligned paral1e $\}$ to the $\langle 100\rangle$ directions in the foil plane with an average spacing of $350 \AA$.. The ordering

*dpa = displacements per atom. 


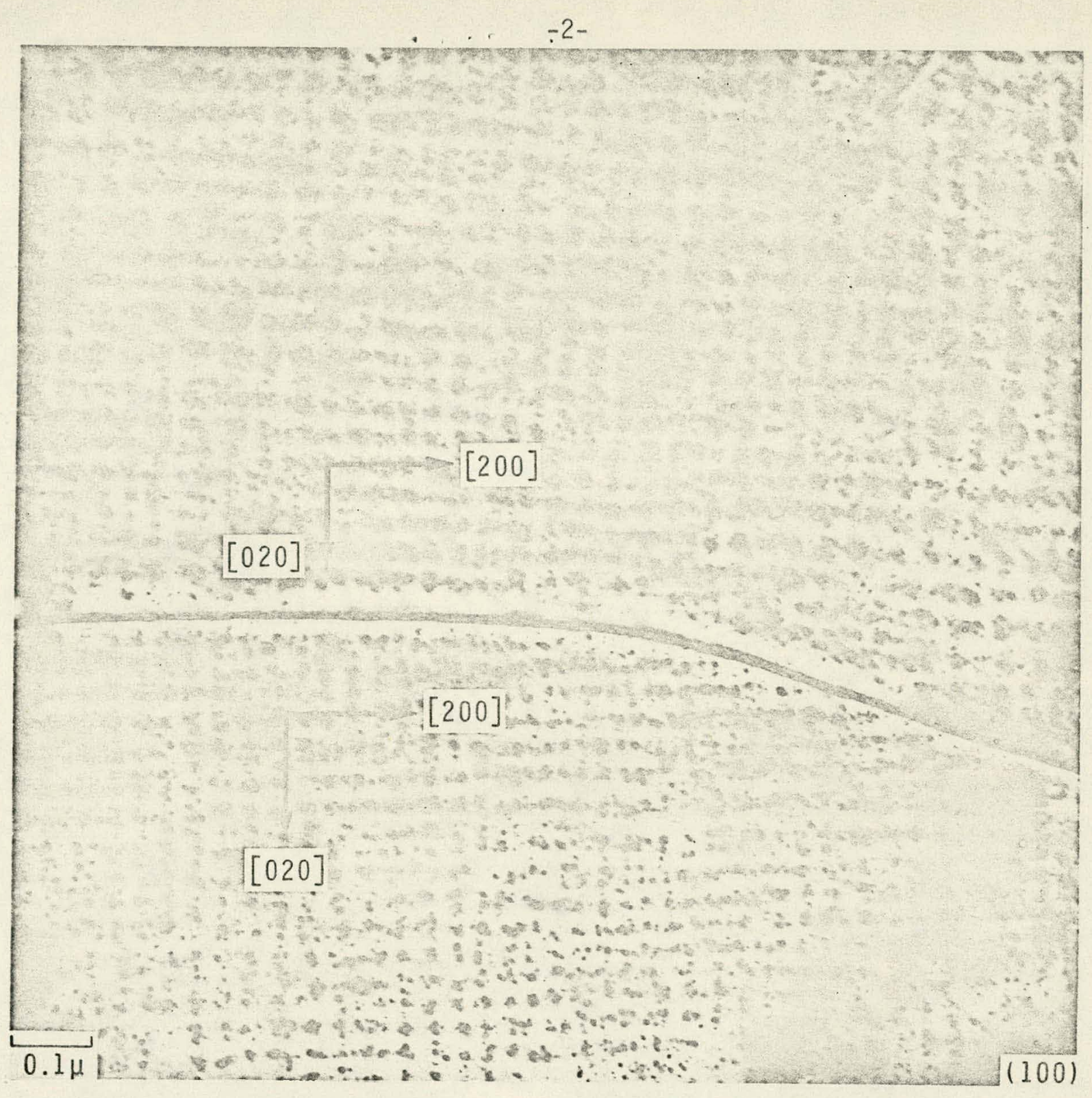

Figure 1. Alignment of the radiation damage in nickel produced by bombardment with $5 \mathrm{MeV} \mathrm{Ni}{ }^{++}$ions to $1 \times 1016$ ions $/ \mathrm{cm}^{2}$ at $370{ }^{\circ} \mathrm{C}$.

extended over entire grains with very little denuding $(<500 \AA$ ) of the damage around grain boundaries as seen in Figure 1. The cluster density is difficult to measure because of overlapping, but it appears to be in excess of $4 \times 10^{16} \mathrm{~cm}^{-3}$.

Examination of the microstructure at high magnification clearly showed the presence of dislocation loops which have no stacking fault contrast and are, therefore, prismatic in nature. The loops are also inclined to the foil plane, and the line of no contrast is parallel lo the $<110>$ direction. Based on the conditions outlined by Thomas 
and Be11, (11) the loops most likely lie on $\{111\}$ planes with a $\frac{a}{2}<110>$ Burgers vector.

The very small black spots could be resolved at high magnification to be squares with sides parallel to the $\langle 100\rangle$ directions. Some examples are circled in Figure 2. Stacking fault tetrahedra should project as squares in this orientation. The existence of stacking faults is confirmed by the presence of streaks in the diffraction spots (insert, Figure 2). The streaks are a result of the reciprocal lattice points extending in a direction perpendicular to the fault which in this case is the <111> direction. (12) The <111> direction projects as the $\langle 110\rangle$ direction in the (100) plane and the insert in Figure 2 shows streaks in the $\langle 110\rangle$ direction.

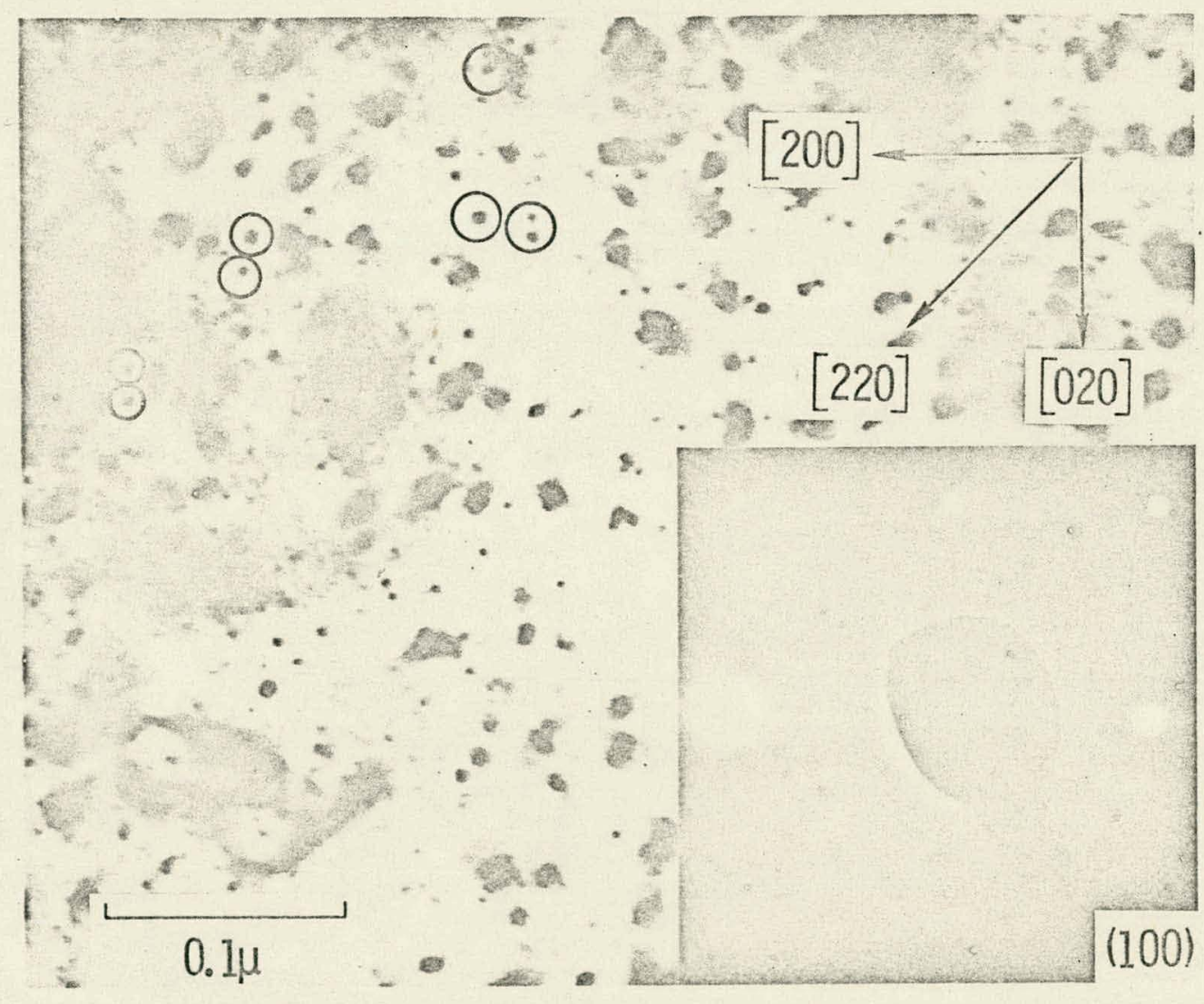

Figure 2. Evidence for stacking fault tetrahedra in ion bombarded $\mathrm{Ni}$. Note square projection of tetrahedra (circled) in (100) orientation and streaking of diffraction spots in the <110 > direction (insert). 
Several conclusions can be drawn from these observations. It is known that interstitials are inherently more mobile than vacancies, and that after irradiation the interstitial type defects tend to be larger but fewer in number than the vacancy type defects. It is then reasonable to conclude that the dislocation loops originate from the interstitial atoms and the stacking fault tetrahedra from the vacancies. Stacking fault tetrahedra have been previously identified in nickel irradiated with neutrons at $50^{\circ} \mathrm{C}$ and annealed at temperature $<500{ }^{\circ} \mathrm{C}$. $(13,14)$ Tetrahedra have also been observed in quenched and annealed nickel. (15) Interstitial loops have been identified in nickel irradiated with neutrons at $50{ }^{\circ} \mathrm{C}$ and subsequently annealed, ${ }^{(13)}$ and have also recently been identified in nickel irradiated directly at $350{ }^{\circ} \mathrm{C} .{ }^{(16)}$ Therefore, previous results would strongly support the concept that the dislocation loops are interstitial in nature and that the remaining vacancies form stacking fault tetrahedra.

The unique feature of the microstructure is the well delineated ordering of interstitial dislocation loops. Furthermore, since the loops align in $\langle 100\rangle$ rows in the (100) plane, the arrangement in three dimensions must be a cubic type of array. This cubic ordering is felt to be a result of loop movement by self climb and/or prismatic glide into a position where the interaction energy between loops is a minimum. Foreman and Eshelby ${ }^{(17)}$ and Kroupa ${ }^{(18)}$ have derived the interaction energy for the particular case of loops lying on parallel planes with equivalent Burgers vectors. One can use their expressions to derive the spatial distribution of constant forces for climb of two paralicl (111) loops with identical $\frac{a}{2}<110>$ Burgers vectors. Figure 3 shows the results of such a calculation for Ni and reveals that loops moving only by self climb should come to rest at a position of $35^{\circ}$ or $65^{\circ}$ to the plane normal. If the rows of loops form only at $35^{\circ}$ to the loop plane normal and repeat this ordering in three dimensions, then such a grouping would produce a fcc stacking. Rotation of a fcc lattice into a (100) orientation would consequently result in a cubic array such as that observed experimentally. A more quantitative analysis is difficult at this time because there are four $\{111\}$ planes in $\mathrm{Ni}$, each with three 


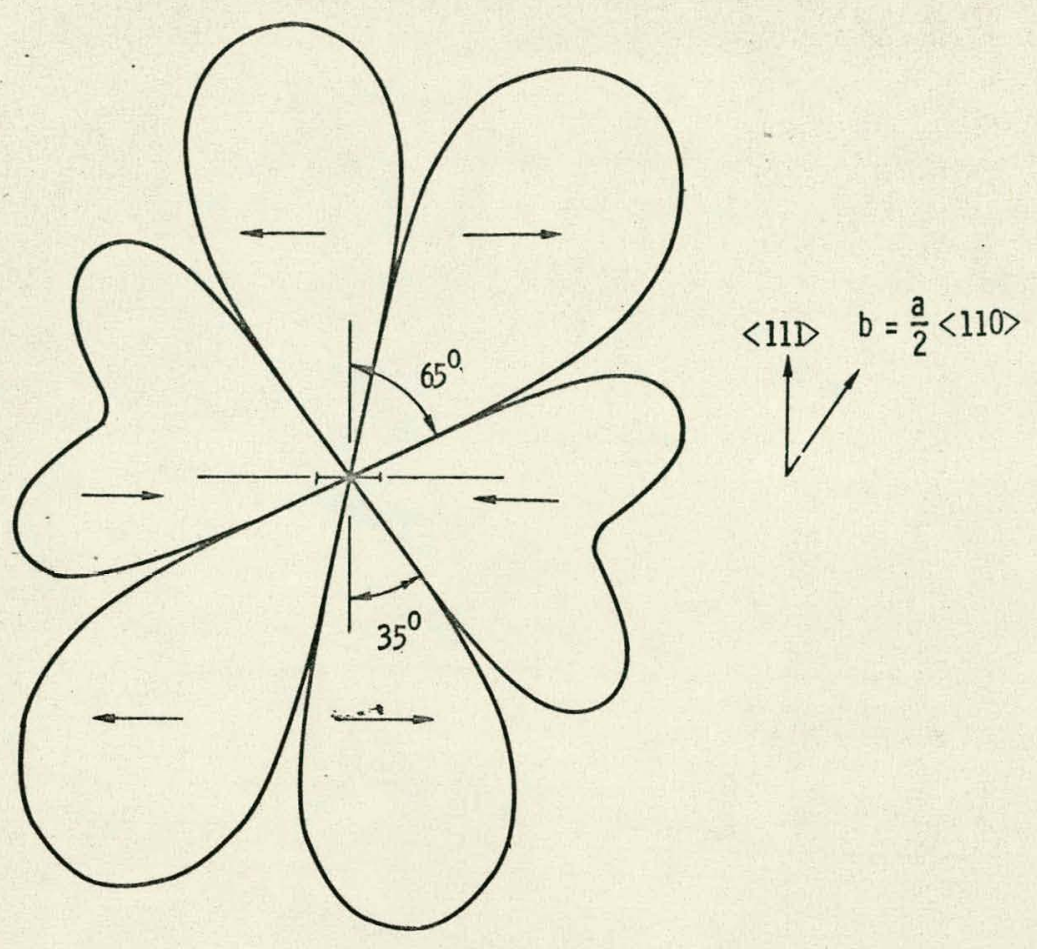

Figure 3. Constant force curve for self-climb between two parallel loops.

possible $\frac{a}{2}<110>$ Burgers vectors. Further work on these complex interactions is in progress.

It can be shown that a structure such as that observed in Figure 1 cannot be caused by prismatic glide alone. Hudson (19) has developed the expressions for the force in the glide directions for two identical loops and his theory would predict that the rows of loops would form at $45^{\circ}$ to the loop plane normal in nickel. This would not produce a cubic array when rotated into a (100) orientation such as that observed in Figure 1.

ORDERED VOID STRUCTURES IN METALS

There have been several independent and simultaneous observations in the past year of three dimensional ordered arrays of voids in metals. $(3-6,20)$ These observations have been made on a wide variety of materials in $\mathrm{Ni}$, Mo, Mo $-0.5 \mathrm{Ti}, \mathrm{TZM}, \mathrm{Nb}$, and $\mathrm{Ta}$ which 
were both ion bombarded and neutron irradiated, with and wi thout inert gases such as helium present during the irradiation. One of the striking features of these observations is that the void super strucutre has the same stacking as the parent atomic lattice (i.e., $\mathrm{fcc}$ in $\mathrm{Ni}$ and $\mathrm{bcc}$ in $\mathrm{Mo}, \mathrm{Nb}$, and $\mathrm{Ta}$ ).

Figure 4a shows a typical fcc cubic array of voids in $6 \mathrm{MeV} S \mathrm{Se}$ ion bombarded $\mathrm{Ni}$. Identical results were obtained from $5 \mathrm{MeV} \mathrm{Ni}$ ion bombarded $\mathrm{Ni}$ foils which contained 3 atomic parts per million of pre-injected helium. Both of these studies were conducted at $525{ }^{\circ} \mathrm{C}$ and they reveal that the threshold for the super lattice formation is approximately $350-400 \mathrm{dpa}$ in $\mathrm{Ni}$.

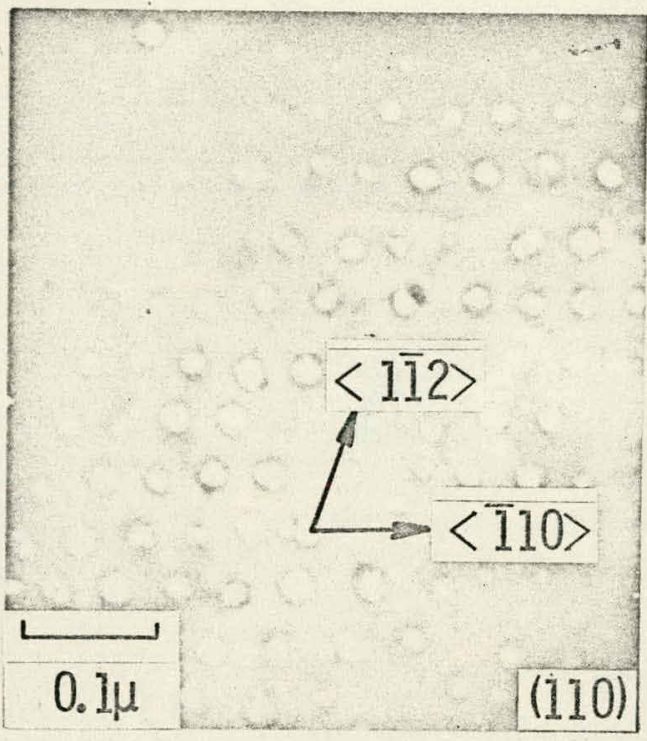

$4 a$

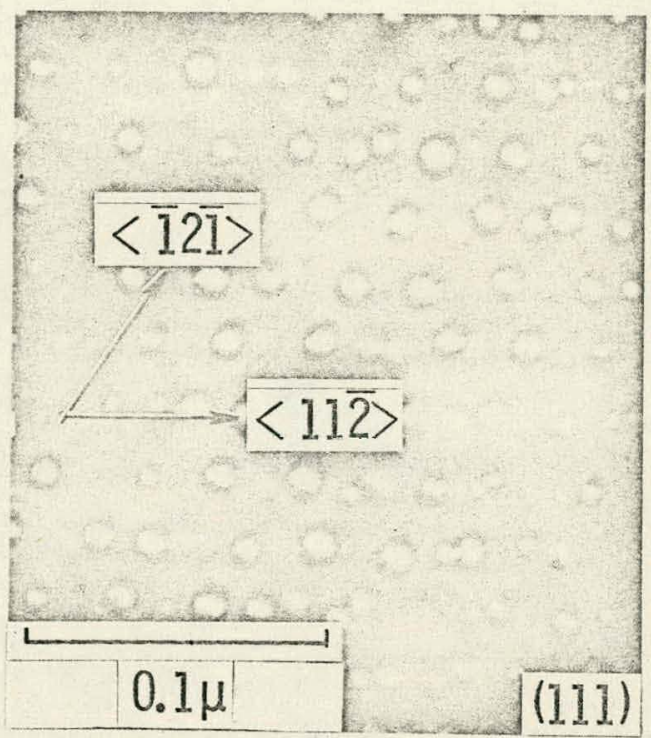

$4 \mathrm{~b}$

Figure 4a. Face centered cubic superlattice of voids in nickel which has been ion bombarded to 400 dpa at $525{ }^{\circ} \mathrm{C}$.

4b. Body centered cubic superlattice of voids in molybdenum which has been ion bombarded to 130 dpa at $900{ }^{\circ} \mathrm{C}$.

Figure 4b exhibits a typical bcc cubic array of voids in $7.5 \mathrm{MeV}$ Ta bombarded Mo. The damage level is approximately $130 \mathrm{dpa}$ and the bcc structure has been confirmed by observations in the (111) and (110) orientations. Similar results were obtained with Nb bombarded with $\mathrm{Ni}$ ions at $800^{\circ} \mathrm{C} .{ }^{(3)}$ 
Figure 5 shows a typical bcc void array found by Evans (4) in Mo bombarded with $2 \mathrm{MeV}$ nitrogen ions at $870{ }^{\circ} \mathrm{C}$ to approximately $100 \mathrm{dpa}$. Projections of the void lattice in the (100), (110), and (111) orientations unambiguously confirms a bcc superlattice in that metal.

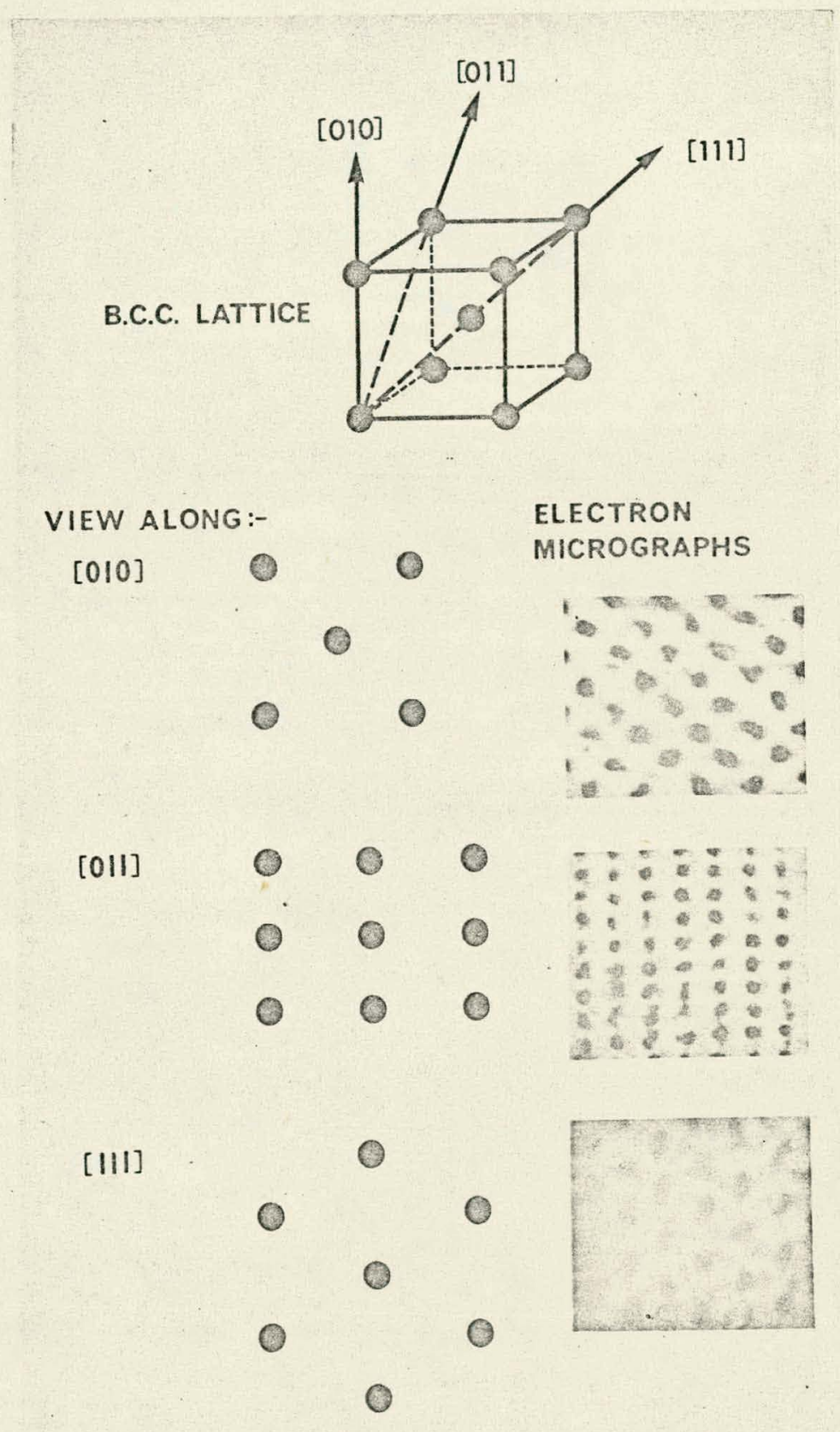

Figure 5. The projections of a bcc lattice along the [011], [010] and [111] directions together with micrographs showing the projections of the void lattice along the same directions. Courtesy of J. H. Evans. 
Wiffen $(5,20)$ has found similar bcc ordered lattices in bcc metals which have been irradiated to the 30 - 40 dpa range. Figure 6 shows typical microstructures of pure Mo, $\mathrm{Nb}$ and Ta. An important feature of this study was that the formation of the superlattice must be

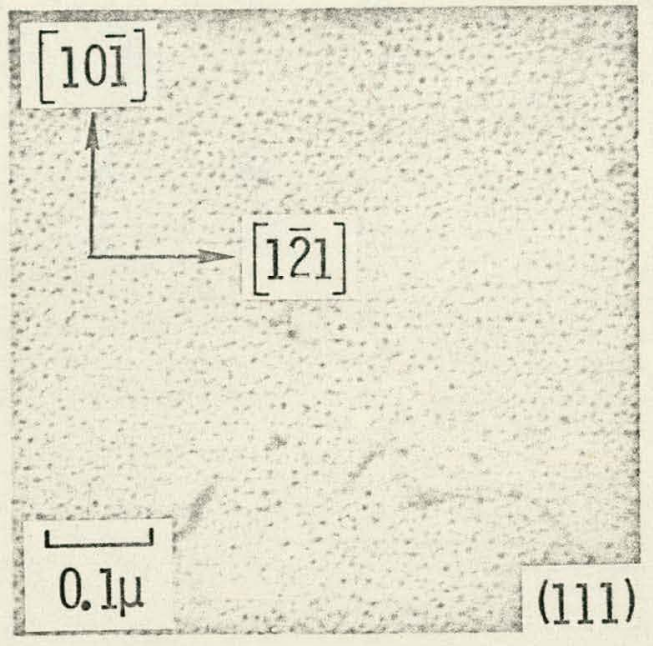

$\mathrm{Ta}$

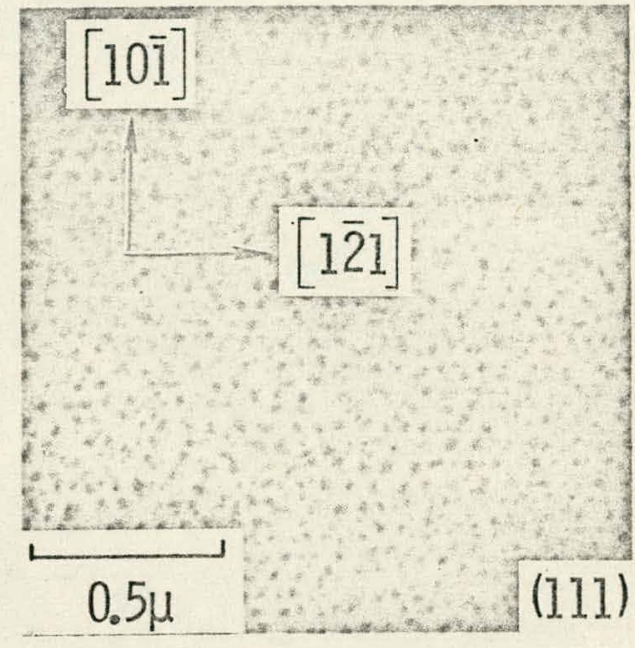

$\mathrm{Nb}$

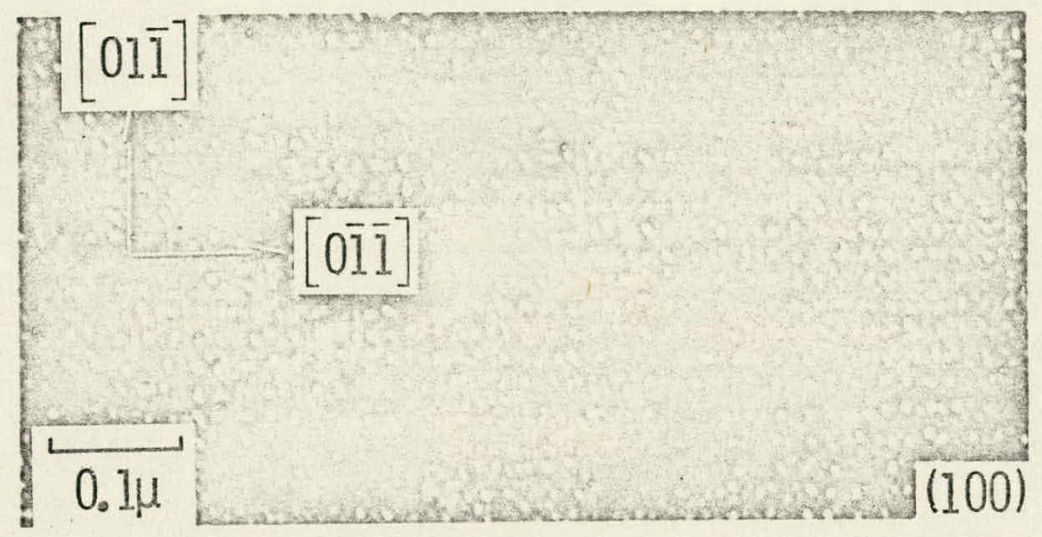

Mo

Figure 6. Ordered void lattices in neutron irradiated refractory metals. Courtesy of F. W. Wiffen.

relatively insensitive to displacement rates. For example, approximately the same results were obtained from Mo which was ion bombarded at $10^{-2} \mathrm{dpa} / \mathrm{sec}$ (see Table I) and that which was neutron irradiated at $10^{-5} \mathrm{dpa} / \mathrm{sec}$. 
The reasons for the void alignment have been explored by Malén and Bullough (21) using the theory of anisotropic elasticity." They concluded that the interation between the displacement fields of the voids was responsible for the ordered arrays: These displacement fields arise from the anisotropy of the elastic constants. Malén and Bullough (21) calculated that the interaction between a faceted void at the origin and another of equal size at $\underline{R}$ is

$$
E(\underline{R})=-\frac{8 d(1-\beta)^{2} p^{\prime 2}}{3 r_{v} \pi C_{44}}\left\{\left(\frac{r_{v}}{R}\right)^{3}-\frac{28 C_{44}}{9 d(1-\beta)} \cdot\left(\frac{r_{v}}{R}\right)^{5}\right\}[3-5 S(4)]
$$

Where $P^{\prime \prime}=$ a surface energy term required to maintain

a faceted void with eight faces.

$$
\begin{aligned}
& r_{v}=\text { radius of the void } \\
& \beta=\frac{c_{12}+c_{44}}{C_{12}+2 C_{44}}
\end{aligned}
$$$$
d=c_{11}-c_{12}-2 c_{44}
$$

$C_{11}, c_{12,} c_{44}=$ elastic constants

$S(4)$ is a geometrical structure factor accounting for the positions of the surrounding voids.

Malén and Bullough (21) find that the ratio of the equilibrium spacing to the void radius should be. $a / r_{v} \cong 8$ in Mo by requiring that the interaction be a minimum at the equilibrium lattice spacing, $a$, $\mathrm{dE}_{2}(\mathrm{a}) / \mathrm{da}=0$ and that $\mathrm{d}^{2} \mathrm{E}_{2}(\mathrm{a}) / \mathrm{da}^{2}>0$ for stability. A similar treatment predicts $a / r_{v} \cong 6$ for $\mathrm{Nb}$.

- Table $I$ * lists the experimentally determined $a / r_{v}$ ratios for all the materials in which void super structures have been found. It is seen that the experimentally determined $a / \dot{r}_{v}$ ratios of $7.7-11$ for Mo, 6.1 - 8.8 for Mo-0.5 Ti and 7.3 for TZM agree well with that theoretically predicted $(21)$ for pure Mo. The agreement for the $a / r_{v}$ ratio in neutron irradiated $\mathrm{Nb}(7.2)$ and that theoretically predicted ( 6 ) is quite reasonable, but it is considerably less satisfactory

* Note that the $i$ on bombardment temperatures have been corrected to equivalent neutron irradiation temperatures according to Bullough and Perrin. (22) 
TABLE I

SUMMARY OF DATA ON ORDERED VOID LATTICES

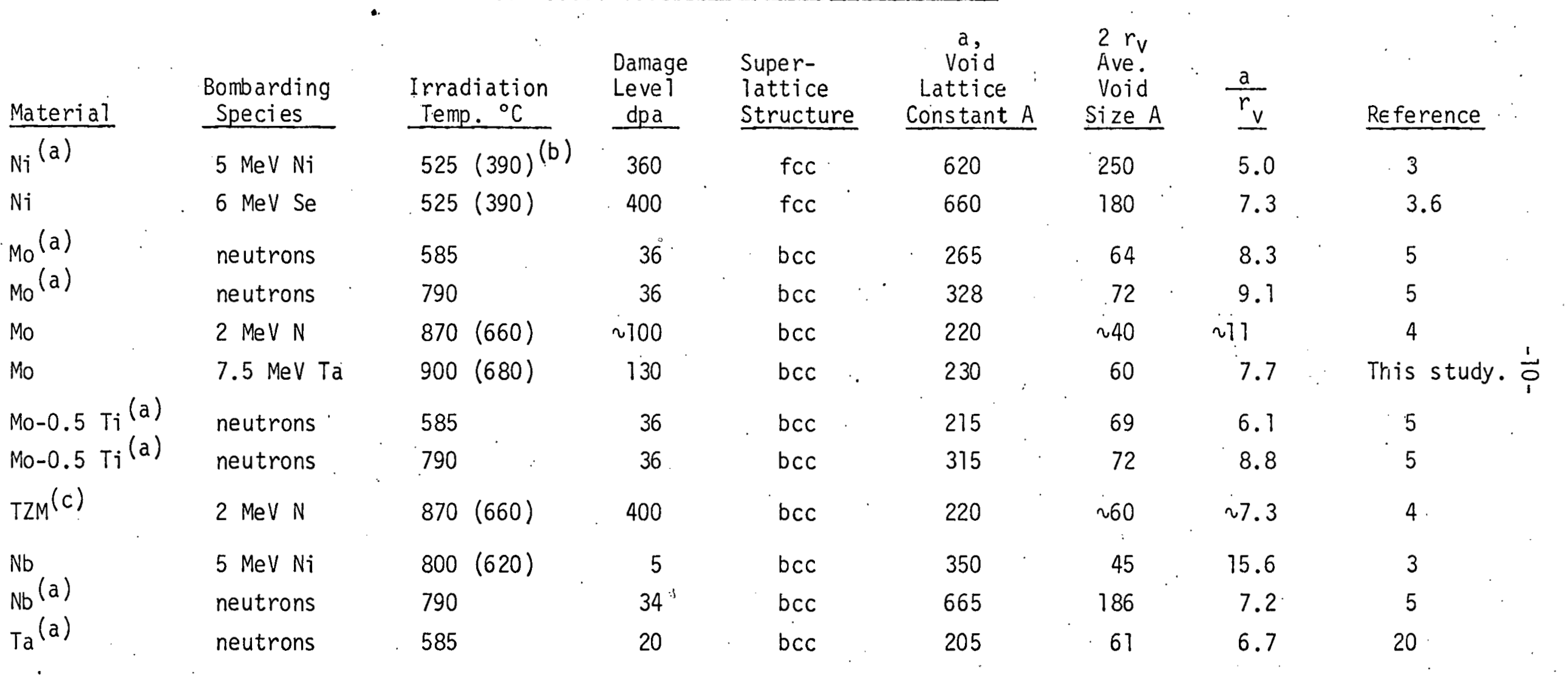

(a) Contains He from pre-injection or produced neutronically.

(b) () Effective neutron irradiation temperature corresponding to $10^{-6} \mathrm{dpa}{ }^{\prime} \mathrm{sec}$.

(c) Nominally $0.5 \mathrm{Ti}-0.7 \mathrm{Zr}-0.03 \mathrm{C}-\mathrm{Ba}$. Mo. 
- in the ion bombarded $\mathrm{Nb}(15.6)$. The theory completely faits to predict ordering in Ta but as Malen and Bullough point out, certain approximations will have to be refined in order to present a more complete result of faceted voids. No theoretical attempt has been published treating the case of fcc $\mathrm{Ni}$ so little can be said about the ordering in that metal aside from the fact that $\mathrm{Ni}$ also has a considerable amount of elastic anisotropy.

The physical significance of the ordered void structure is that it may limit the amount of void induced swelling in metals when the equilibrium $a / r_{v}$ value is reached. At this point, the voids would be the predominant sinks for both vacancies and interstitials.

There will be no net growth if equal amounts of both vacancies and interstitials add to the voids and saturation of the void induced swelling should occur.

\section{REFERENCES}

1. "Symposium on the Nature of Small Defect Clusters," AERE R 5269 , ed. by .J. Makin, 1966.

2. M. W. Thompson, Defects and Radiation Damage in Metals, Cambridge University Press, Cambridge, 1969.

3. G. L. Kulcinski, J. L. Brimhall and H. E. Kissinger, International Conference on Voids in Metals held in Albany, NY, June 1971, to be published.

4. J. H. Evans, ibid, see also AERE-6647, 1971.

5. F. W. Wiffen, ibjd.

6. G. L. Kulcinski, J. L. Brimhall and H. E. Kissinger, J. Nucl. Mat., Vo.]. $40,1971$.

7. G. L. Kulcinski, A. B. Wittkower and G. Ryding, Nucl. Instr. \& Methods, 94, 365, 1971 .

8. H. R. Brager, H. E. Kissinger and G. L. Kulcinski, Radiation Effects, $\underline{5}, 281,1970$.

9. G. L. Kulcinski, D. G. Doran and J. J. Laidler, Radiation Effects, I. 195,1971 .

10. D. G. Doran and G. L. Kulcinski, Radiation Effects, 9, 283, 1971.

11. G. Thomas and W. L. Bc11, p. 179 in Lattice Deferts and Their Interactions, ed. by $R$. R. Hasaguti, Gordon and Breach, 1967. 
12. P. A. Hirsch, A. Howie, R. B. Nicholson, D. W. Pashley and M. J. Whelan, Electron Microscopy of Thin Crystals, Butterworths, 1965.

13. J. L. Brimhall and B. Maste1, J. Nucl. Mat., 33, 186, 1969.

14. A. Bourret and A. M. Levelut, Phys. Stat. Sol., 37, K 101, 1970.

15. P. Humble, M. H. Loretto and L. M. Clarebrough, Phil Mag., 15 $297,1967$.

16. J. L. Brimhall and B. Mastel, unpublished work.

17. A. J. E. Foreman and J. D. Eshelby, AERE-R-4170, 1964.

18. F. Kroupa, p. 275 in Theory of Crystal Defects, ed. by B. Gruber, Academic Press, 1966.

19. B. Hudson, Phil. Mag., 10, 949, 1964.

20. F. W. Wiffen, to be published.

21. K. Malèn, and R. Bullough, International Conference on Voids in Metals, held in Albany, NY, June, 1971, to be published.

22. R. Bullough and R. C. Perrin, "Irradiation Effects on Structural Ailoys for Nuclear Reactor Applications," ASTM-STP-484, p. 317, 1970.

23. J. P. Hirth and J. Lothe, Theory of Dislocations, p. 761, McGrawHi11, New York, 1968. 